\title{
LUT
}

University

\section{Understanding and Fostering Collective Ideation: An Improvisation-Based}

\section{Method}

Nisula Anna-Maija, Blomqvist Kirsimarja

This is a Author's accepted manuscript (AAM) version of a publication

published by Springer, Cham

in Knowledge Management, Arts, and Humanities. Knowledge Management and Organizational Learning

DOI: 10.1007/978-3-030-10922-6_3

Copyright of the original publication: () Springer Nature Switzerland AG 2019

Please cite the publication as follows:

Nisula AM., Blomqvist K. (2019) Understanding and Fostering Collective Ideation: An Improvisation-Based Method. In: Handzic M., Carlucci D. (eds) Knowledge Management, Arts, and Humanities. Knowledge Management and Organizational Learning, vol 7. Springer, Cham

This is a parallel published version of an original publication. This version can differ from the original published article. 


\title{
Understanding and fostering collective ideation: an improvisation-based method
}

\author{
Anna-Maija Nisula * \\ School of Business and Management \\ LUT University \\ Yliopistonkatu 34, 53850 Lappeenranta \\ E-mail: anna-maija.nisula@lut.fi \\ Kirsimarja Blomqvist \\ School of Business and Management \\ LUT University \\ Yliopistonkatu 34, 53850 Lappeenranta \\ E-mail: kirsimarja.blomqvist@lut.fi \\ *corresponding author
}

Nisula \& Blomqvist, (2019) Understanding and fostering collective ideation: an improvisation -based method. In Knowledge Management, Arts and Humanities. Interdisciplinary Approaches and the Benefits of Collaboration. Eds Handzic, M. and Carlucci, D. Springer International Publishing, ISBN 978-3-030-10921-9. DOI 10.1007/978-3-030-10922-6

\begin{abstract}
Although the collective view is receiving increasing attention in research, this perspective is missing from the approaches for fostering creativity and ideation. The present study aims to fill this research gap by understanding ideation as a collective phenomenon and by introducing a novel method for fostering collective ideation. The study builds on current research on knowledge creation, collective creativity, idea generation, and collective theatrical improvisation to introduce an approach for fostering collective ideation. In addition, as a secondary goal, the study provides empirical findings about the implementation of collective ideation in thirteen distinct cases. The study builds links between knowledge creation and collective theatrical improvisation, and thus, highlights social and affective aspects of collective ideation as a knowledge creation.
\end{abstract}

Keywords: ideation, collective ideation, idea generation, knowledge creation, collective improvisation, theatrical improvisation 


\section{INTRODUCTION}

In a world of high complexity, multiplicity, specialized expertise, and fast change, novel creations demand integration of knowledge and input by multiple individuals, and yet the forms of collaboration are increasingly varied (Wagemen, Gardner and Mortenston, 2012). The view that novel ideas are joint creations is acknowledged by many scholars (Björk, 2012; Björk et al., 2016; Catmull, 2008; Hargadon and Bechky, 2006; Harvey, 2014; Harvey and Kou, 2013; John-Steiner, 2000; Kohn, Paulus and Choi, 2011), and knowledge creation theories (Erden, von Krogh and Nonaka, 2008; Nonaka and Toyama, 2003) second this view.

Researchers have studied the collective view as collective engagement in creative tasks (Harvey and Kou, 2013), collective emergence (Sawyer and deZutter, 2009), creative collectives (Hargadon and Bechky, 2006; John-Steiner, 2000), collective creativity (Drazin, Glynn, Kazanjian, 1999), creative synthesis (Harvey, 2014), and convergent creativity (Harvey, 2013) but have not associated the collective view with facilitation of ideation as a collective phenomenon. Although the collective creativity is receiving increasing attention, in facilitation of creativity and ideation specifically, cognitive stimulation, based on divergent and convergent thinking of creativity, still dominates (Harvey, 2014; Nisula and Kianto, in press). The problem is that in the approaches that constitute various sequential idea treatment activities ranging from generating ideas to selecting the best ones (Diehl and Stroebe, 1987; Osborn, 1953; Paulus and Yang, 2000), the emergence of novel ideas from the situated interaction and interpersonal dynamics of group members' knowledge, perspectives, and creativity may suffer. Therefore, the collective creative potential of the group remains hidden and unused. Harvey's (2013) findings support this assumption: She found that brainstorming kind of idea process does not necessarily serve groups of deep diversity well. Hence, it is likely that sequential idea processes do not support synergistic creativity, that is, neither the emergence of collective group processes nor people's engagement in a shared single outcome (Harvey, 2013; Harvey and Kou, 2013). Although, socio-emotional (e.g. Fisher, 1992; Russ, 2013; Paulus and Brown, 2003) and cognitive-affective (Amabile, 1983) aspects have been acknowledged in creativity research, they have received less attention than the facilitation of cognitive ideation.

When creativity is seen as a collective, that is, as a social and interpersonal activity that occurs within social settings in which people engage, the interaction between people appears the central source of creativity (Sawyer and deZutter, 2009). Then, in addition to cognitive aspects, social and affective aspects of creativity become vital (e.g. Csikszentmihalyi, 1999; Harvey, 2014; Handzic and Chaimungkalanont, 2004). More specifically, novel solutions arise when people interact, share knowledge and perspectives, and show their emotions, which interaction is simultaneously an unfolding social setting and an enacted collective practice. A planned or correct way to jointly create 
does not exist; instead, each joint creation demands and builds its unique social settings (Dyck et al., 2005; Nemeth, 1997; Nonaka and von Krogh, 2009) and processes (Elsbach and Kramer, 2003; Erden, von Krogh and Nonaka, 2008; Hargadon and Baechky, 2006; Harvey, 2014; Unsworth, 2001). This aligns with any creative achievement, which tends to transcend the existing order with a new organization to open room for novelty (Hjort, 2004). Given that groups have more knowledge than their members, using groups' synergistic creative potential for a shared course demands support and facilitation, because groups do not necessarily or naturally work as a collective.

As ideation (Runco, 2010) is central in creativity, and our knowledge of ideation as collective activity is limited, the following research question guided our work: How can ideation as a collective activity be enabled and facilitated? In the present study, we understand ideation as a collective phenomenon and introduce a novel method to facilitate ideation. We believe that groups' collective creative potential for collective ideation derives from the dynamics in cognition, social interaction, and affective (emotional) state of collaboration, which are must-have aspects in searching for novel solutions and making discoveries (Csikszentmihalyi, 1999). Specifically, with play, the social interaction and affective state, like joy, enthusiasm and passion, are at the core of human creativity (Csikszentmihalyi, 1988, 1999; Huizinga, 1949; Mainemelis and Ronson, 2006; Ross, 2013; Nisula and Kianto, 2018). We present that to foster synergistic creativity and the use of the collective creative potential of the group all these aspects must be considered, but the social and affective aspects deserve special attention. In addition, we argue that the collective processes vital for collective ideation can be fostered by specific and conscious facilitation and organization of the collective ideation.

By building on the research on idea generation (Diehl and Stroebe, 1987; Nijstad et al., 2002; Osborn, 1953), collective emergence (Sawyer et al., 2003; Sawyer and deZutter, 2009), collective engagement (Harvey and Kou, 2013), collective creativity (Hargadon and Bechky, 2006; Harvey, 2014), convergent creativity (Harvey, 2013), play (Csikszentmihalyi, 1988, 1999; Huizinga, 1949; Mainemelis and Ronson, 2006), and knowledge creation (Nonaka and Toyama, 2003), we introduce a facilitation method for collective ideation that highlights the social interaction and affective state in a group. Then, we illustrate use of the method through experiences from thirteen collective ideation cases. Through discussion, we draw conclusions and suggest future directions for scholars on collective creativity, knowledge creation, and knowledge management. 


\section{THEORETICAL BACKGROUND}

\section{Ideation as collective activity}

In line with many scholars (Björk, Magnusson, Magnusson, Olsson and Sukhov, 2016; Hammond et al., 2011; Hatchuel and Weil, 2009), we understand an idea as a concept that is not fully defined but is clear enough to serve as a stimulus for users, producers, or investors. The term ideation describes a process for producing ideas. According to Runco (2010), ideation involves generation, evaluation, judgments, and decisions about ideas. Harvey and Kou (2013) also understand idea generation and evaluation are essentially embedded in groups' collective creativity. As generating novel ideas is fundamentally a process of building novel associational connections and unconventional links between atypical elements or nodes of knowledge in the interaction between people, collective ideation is better to understand as an interdependent and unfolding process (Sawyer and deZutter, 2009) to create new knowledge (Nonaka and Toyama, 2003) by bringing the knowledge, creativity, and perspectives of diverse people together to strive toward a shared creative outcome. Yet, the collective ideation is differentiated from group ideation, in which the aim is to generate and collect many ideas either as solo or group (nominal or interactive) ideation or in various sequential combinations of these two for the following idea treatment (combining, evaluation, and selecting) processes (Brown et al., 1998; Diehl and Stroebe, 1987; Heslin, 2009; Nijstad et al., 2002; Osborn, 1953).

In contrast to structured ideation (distinct divergent and convergent phases), collective ideation considers idea generation and evaluation as essentially embedded in joint creation throughout the process. In collective ideation people make decisions continuously, throughout the ideation process about the direction of the ideation, and therefore, become committed in joint creation (Harvey and Kou, 2013). In fact, the people's mutual contributions (e.g., expressing ideas, responding and building on others' contributions), reflect people's attention and engagement, and trigger the emergence of new knowledge, that is, knowing in practice (Amin and Roberts, 2008; Cook and Brown, 1999).

Unlike sequential solo and group ideation, collective ideation is interdependent. Thus, no one individual determines the course of action or the outcome. In contrast, people's situated contributions (Choi, Sung and Cho, 2014; Harvey, 2014; Harvey and Kou, 2013; John-Steiner, 2000) determine what is actualized (Woodman et al., 1993), and the outcome of the ideation results in the interwoven contributions of multiple individuals and is, therefore, a collectively composed and shared solution. Thus, collective ideation increases the likelihood that people engage in the creative process and the shared outcome. 
As the peoples' intense interaction is central for collective ideation (e.g. Sawyer and deZutter, 2009), groups' social interaction and affective state become specifically important. Namely, it is not only the voiced ideas of others but also non-verbal and mutual communication (gestures and others' behavior), individuals' intuition and perceptions of other persons affective state (passion and enthusiasm), and environmental aspects (voices and atmosphere) that influence people's contributions and thus, joint creation.

Overall, collective ideation is an emergent and unconstrained process rather than a predictable process, as it relies on people's mutual communication, interaction, and situated actions for a shared course. Thus, collective ideation is open to atypical connections of ideas and knowledge, and any contribution can open up new directions for a common creative achievement.

\section{Fostering collective ideation: insights from collective improvisation}

As collective ideation is a different kind of process compared to cognition-based ideation, it demands a specific kind of stimulation. In contrast to various techniques and tools (e.g., Brainstorming or Lateral thinking) that are often used to stimulate ideation, it is appropriate to look closely at the underlying aspects of collective ideation, that is, the practices through which sufficient circumstances and space for interaction and interpersonal connectivity among people could be enabled. Then, these underlying aspects are likely to foster the central processes of collective creation identified by Harvey (2014): collective attention, building on similarities within different perspectives, and enacting ideas to address cognitive, social and affective aspect of joint creation. Thus, facilitation of collective ideation should consider stimulation of not only cognitive but also social and affective aspects of creativity (Csikszentmihalyi, 1999; Nisula and Kianto, 2018).

As very few approaches for facilitating collective ideation exist, we draw from collective theatrical improvisation, which is probably the most collective and dynamic form of human interaction and creativity. Theatrical improvisation serves well as a model for social and emergent collective ideation, because it is highly collective, grounded by interdependence, mutual attention and support, shared responsibility and leadership, ensemble, and building on others' contributions (Koppett, 2001; Sawyer and deZutter, 2009; Spolin, 1977), which are characteristics of any collective creation. In addition, the collective processes identified by Harvey (2014) are involved in collective theatrical improvisation. Collective attention, real-time alertness, is the core of collective improvisation (Sawyer and deZutter, 2009; Spolin, 1977), in which participants are alert to, recognize others' contributions, and respond to them. In other words, collective improvisation is building on others' contributions, which simultaneously builds a shared creative performance, the future of which is still open. This can refer to building on similarities presented by Harvey (2014), in a sense that in 
improvisation people accept others contribution, agree with it, and make ad hoc decisions to respond and add to it. Certainly, synergistic creativity (Harvey, 2014, 2013) is differentiated from collective improvisation in a sense that in synergistic creativity people have more time to explore and communicate similarities. Further, in collective improvisation ideas become enacted when they are considered and integrated into performance, that is, into the chain of contributions of diverse actors.

The collective improvisation is grounded by play, like joy, associating, mishaps, and seeing mishaps as sources of creativity (Koppett, 2001; Spolin, 1979), which can foster social, cognitive, and affective aspects of collective ideation. Scholars present that play can foster interaction and relationships (Huizinga, 1949; Mainemelis and Ronson, 2006), joy and enthusiasm (Ekvall, 1996), and the well-being of the group (Huizinga, 1949; Roos and Roos, 2006), which are socio-emotional aspects that are less addressed in cognition-focused idea generation. Play also foster thinking within (i.e., imagining, constructing together, and communicating) and demonstration of embodied knowledge in action (Roos and Roos, 2006), which is central for collective ideation. In addition, play can stimulate cognition and fosters making novel distinctions (Barry and Meisiek, 2010), as well as experiments to transfer ideas into action (Dodgson, Salter and Gann, 2005). As play is about engagement, and becoming a part of the experience of play (Gadamer, 1989; Huizinga, 1949), it reflects engagement among the group members. This is specifically important for people's engagement in others' ideas in collective ideation. As an engagement, play can stimulate individuals' cognitive, affective, and motivational dimensions of the task, while in a diversion play can stimulate the social and interpersonal dynamics that encourage creativity (Mainemelis and Ronson, 2006).

Finally, collective improvisation can transcend established social behaviors and practices to enable new organization (Hjort, 2004, 2005) and room for creativity (Nisula and Kianto, 2018). This is because collective improvisation relies on people playing without a script under unfolding mutual support and interaction (Sawyer and deZutter, 2009; Spolin, 1977), which is simultaneously a social and evolving practice, an unfolding process and a performance. Thus, improvisation is a shift from habitual thinking and behavior (Moorman and Miner, 1998) to moving between opposites (Montuori, 2003) and means and ends (Mainemelis and Ronson, 2006), which are also characteristics of play (Huizinga, 1949).

\section{ASSIGNMENT FOR FOSTERING COLLECTIVE IDEATION}

\section{Assignment design principles}

In this section, we describe the key principles that are the basis of the design of collective ideation assignment. The assignment for collective ideation aims to resemble collective improvisation, which occurs without a script in interactions between participants. We believe that 
such circumstances enable and support collaborative emergence (Sawyer and deZutter, 2009) and collective synergistic creativity (Hargadon and Bechky, 2006; Harvey, 2013, 2014), and support collective processes, such as interdependence, collective attention, enacting ideas, and building on similarities, which are involved in collective improvisation and collective ideation. Thus, collective ideation is fast, which triggers spontaneity and helps to deviate from conventional social practices and habitual behavior (e.g. Moorman and Miner, 1998) and it thereby builds room for the enacted collective processes in situ among the group members.

The given task/problem is challenging, atypical and imaginative (with atypical ingredients), and it demands a high level of creativity and intense collaboration among group members. Scholars present that a specific or challenging goal stimulates ideation (Litchfield, Fan and Brown, 2011; Locke and Latham, 1990), which can be stated, for example, by the instruction "be creative" (Harrington, 1975; Litchfield Fan and Brown, 2011; Shalley, 1991). In addition, the assignment of the task is open, which is found to foster creativity. Open problems provide freedom for group to discover and identify the problem and think creatively (Csikszentmihalyi, 1988; Grawitch, Munz and Kramer, 2003; James, Clarks and Cropanzano, 1999; Sawyer and deZutter, 2009) and to adjust the problem from the point of view of group members' specific interests, knowledge, and perspectives (Grawitch, Munz and Kramer, 2011). This is likely to stimulate group members' commitment and collective attention and the emergence of new knowledge. Further, the task involves a pitch, presenting a shared outcome for the audiences, which is likely to increase group members' engagement in shared collective ideation. As the group's task is to create a single shared idea for a specific target group, they need to consider the usefulness of their idea for the target group and for investors, which refers to the important and often ignored prosocial aspect of creativity. Thus, when people in ideation focus on goals for others' benefit (i.e., prosocial aspects) it may foster the usefulness of the ideas (Grant and Perry, 2011).

The imaginative character of the given task/problem aims to nurture playfulness and socioemotional aspects of collective ideation. Play is about creativity (Dodgson, Salter and Gann, 2005; Huizinga, 1949; Mainemelis and Ronson, 2006), and it can foster cognitive, social and affective aspects of interaction, and the development of collective group processes. Specifically, the playfulness comes from the imaginative assignment and by using unconventional combination of elements in the task. We assume that in a spontaneous interaction with unfamiliar partner people have less time and opportunity to judge themselves and their thoughts (ideas). Instead, they have to be open minded, alert, listen, and respond to the other person's suggestions.

The groups involve people who are unfamiliar with each other, to support collective emergence and to increase the likelihood of diversity. When group members do not know each other 
from the past, they do not have expectations for the other person, predetermined roles or hierarchies, or shared stable practices. In research, diversity is associated positively with group performance (Nemeth, 1986; Paulus and Yang, 2000), creativity, and innovation (Bantel and Jackson, 1989; Harrison and Klein, 2007). Diversity in knowledge fosters building novel links and associative connections between previously unrelated aspects (Bartunek, Gordon and Weathersby, 1983; Cohen and Levinthal, 1994) and increases the likelihood of synergistic creativity (Harvey and Kou, 2013; Kurtzberg and Amabile, 2000) and an outstanding outcome (Simonton, 1999). However, scholars also show mixed findings (Guzzo and Dickson, 1996; Harrison and Klein, 2007; Van Knippenberg and Schippers, 2007). For example, Harvey (2013) found that diversity in perspectives stimulates idea generation but hinders idea convergence.

In this study, the assignment involved sketching within ideation, as well as in presenting the final solution, that is, an idea for the audience. Harvey (2014) presents that collective ideation is stimulated by enacting ideas, for example, through sketching with pictures, stories, performances (Nisula et al., 2015; Oikarinen and Kallio, 2012; Phillips, 1995), or making prototypes (Hargadon, 2002). Ideating by sketching makes knowledge and others' perspectives visible to others, and enables group members to seek a shared view by playing with ideas and building on others' contributions and thus, create new knowledge.

\section{The procedure for collective ideation}

We next describe the procedure for collective ideation. There are four steps: group formation, assignment for collective ideation, pitch, and evaluation. (Appendix I gives a more detailed description of the assignment.)

Group formation: In the group formation step, the participants are grouped into groups of two to five people, so that they are strangers to each other (they do not know each other or they have not worked together in the past, which increases the likelihood of diversity in a group and fosters the emergence of novel and unfolding interaction among group members.

The assignment for collective ideation: First, the groups are assigned to ideate collectively a product, process, or service idea for the target group based on three random words: 1) Object/artefact, 2) Activity (what the solution does), and 3) Target group (users for whom the group generates the product/service). Each group has different words. Second, the groups are assigned to illustrate their idea (solution) on paper. 


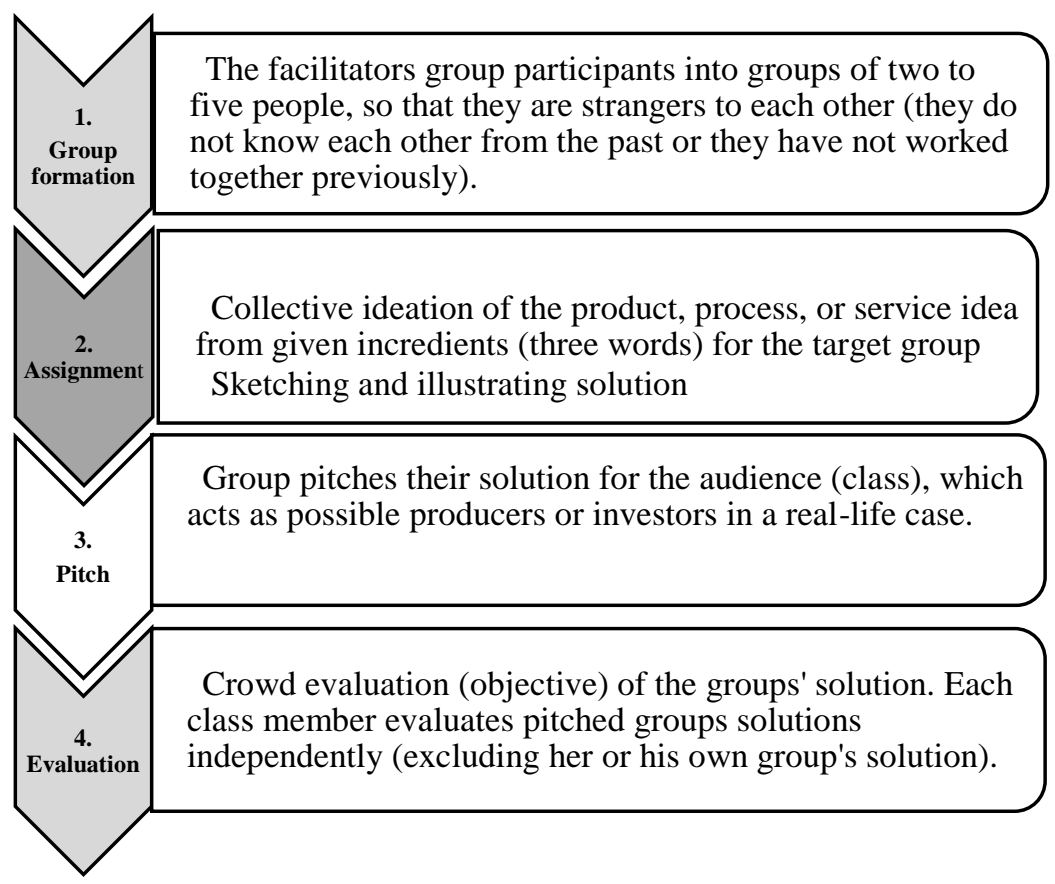

Figure 1: Collective ideation procedure.

Pitch: Third, the groups are assigned to pitch their solution to the audience (class) in order to get funding for further development of the idea. In real life, the audience could be possible investors.

Crowd evaluation: Each solution is evaluated by the crowd after each pitch, so that each participant evaluates each group's solution independently (excluding the participant's own group solution) with a structured evaluation form, with the following items (scale from 1 ("not at all") to 5 ("very"): How creative is the group's solution (novelty)? How insightful is the group's solution (outstanding)? How clear is the group's solution (understandable)? Would you invest in this idea (usefulness, that is, the solution has potential for further development, and I am ready to fund it and therefore, encourage the group to develop it further)? These items align with well-known criteria for creative outcomes: novelty, usefulness (e.g. McKinnon, 1962). 


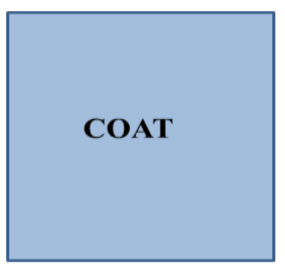

1. Object, artefact

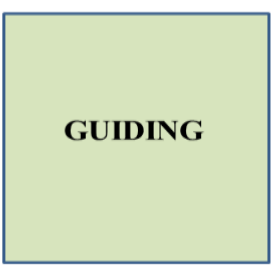

2. Function, activity How artefact could serve or help
target roup?

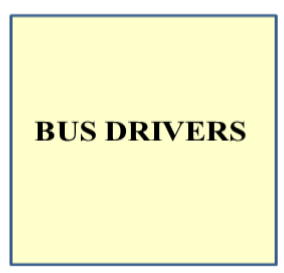

3. Target group Uses of the solution

Figure 1. Sample of the given incidental ingredients for the assignment.

\section{IMPLEMENTATION OF THE COLLECTIVE IDEATION}

To illustrate the use of collective ideation, we report its implementation in thirteen distinct cases. In each case, we created sufficient circumstances for collective ideation with the following principles and organization: First, we grouped people who did not previously know each other into pairs (groups of two persons). The dyad is the simplest target for studying interpersonal dynamics (Bakeman and Beck, 1974). Second, the task of the pair was to ideate collectively an idea or business concept from incidental and imaginary ingredients and then to pitch the groups' shared idea to the audience. Third, the duration for collective ideation was short and limited (25 to $30 \mathrm{~min}$ ). Overall, the assignment and organization of the collective ideation aim to foster the collective process of ideation.

\section{Data collection and analysis}

We collected data from the collective ideation cases via open survey questions. The participants responded voluntarily to the survey. Specifically, the three open questions in the survey constitute the data for this study. In the open survey questions, we captured participants' experiences with collective ideation with the question, "How did you experience the collective ideation event?" The second open question asked about the possible utilization of this kind of ideation event: "Where would you use this kind of event?" The third open question requested open comments and feedback. In addition, the experiences of scholars (Denzin and Lincoln, 1994) and the feedback discussions after each collective ideation case directed the interpretation of the data. For the present study, we analyzed data from the perspective of the research question. 
We adopted qualitative content analysis (Eriksson and Kovalainen, 2016) to analyze the open survey questions, which is appropriate when the quantification of the data is not the goal and when the categorization of the codes needs flexibility and movement between data and theory. NVivo 12 software was used to support the analysis. First, the data were categorized into broader themes, which were then analyzed in more detail by labeling the first-round codes with a data-driven manner. Then, the content of the codes was defined, and the first-round codes were collected under similar contents. The code maps are displayed in Appendix III and Appendix IV.

Until now, the assignment for collective ideation was implemented as a dyadic ideation in thirteen distinct cases in 2013-2018 (Appendix II). Altogether, 440 participants were involved in the collective ideation, of whom 369 responded to the survey. The participants are adult working university students $(\mathrm{N}=235)$ and employees of three large organizations $(\mathrm{N}=134)$.

Of the respondents, $61.0 \%(\mathrm{~N}=225)$ were female and 35.8\% $(\mathrm{N}=132)$ male $(3.3 \%(\mathrm{~N}=12$ were missing values). In terms of educational attainment, the distribution of the respondents was as follows: $1.4 \%(\mathrm{~N}=5)$ comprehensive school, 6.8\% $(\mathrm{N}=25)$ vocational degree, 4.9\% $(\mathrm{N}=18)$ matriculation examination, 76.4\% ( $\mathrm{N}=282)$ academic degree (Master's degree or higher), and 7.0\% (26) other education $(3.5 \%(\mathrm{~N}=13$ were missing values). The age distribution was as follows: $18.5 \%(\mathrm{~N}=57)$ were younger than 30 years old, 55.86\% (N=206) were between 31 and 50 years old, 23.8\% (N=88) were between 51 and 60 years, and 3.8\% ( $\mathrm{N}=14)$ were older than 60 years old $(1.1 \%(\mathrm{~N}=4$ were missing values).

\section{FINDINGS}

The findings show that the collective ideation facilitation yielded mainly positive experiences and feelings among the participants, without ignoring a few contradictory experiences and feelings.

\section{Affective aspects of collective ideation: emotionally positive experiences}

We found that collective ideation yielded mainly positive experiences, which were categorized under constructs: emotionally positive experiences, new and fresh experiences, and expanding experiences (Appendix III). The largest category was emotionally positive experiences, such as fun, nice, inspiring, great, pleasurable, and interesting (Appendix III). Sample quotes are "Great fun", it was nice", "Inspiring", "Great", and "Enjoyable". All these expressions (words) and experiences reflect experienced play and positive affect, and show that the developed collective ideation really fosters affective aspects of collective ideation. The second largest group of positive expressions yielded new and fresh experiences (refreshing, different, variation, new, and surprising) 
for the respondents. Sample quotes are "Different way to ideate and make impossible possible", "Energizing", and "Awesome". The third group of experiences was collected under the title "Expanding experiences", which includes concepts such as breaking boundaries, creative thinking, and liberating. Sample quotes are "triggers thinking", "eye-opening, "out of the box", and "Creative - let it go, fly!"

We also found contradictory experiences, as a few single respondents considered collective ideation difficult. For respondents who are not familiar with creative work or consider themselves non-creative, it might be difficult to throw themselves into fast collective ideation with an unfamiliar other. Expressions such as, "Creativity and innovation is not my strength" and "It was difficult, because you are not familiar with creativity - needs exercising" illustrate respondents' experiences. Another reason for unpleasant experiences was the unpleasant group work, as the following quotes illustrates: "It was alone ideation!" and "We must have been on different wavelength, or at least we could not connect (at the cognitive level). As a human she is certainly ok". This reflects that the social interaction and related dynamics between the participating individuals did not work, and collective ideation did not occur. In addition, one respondent noted, "This kind of task does not fit me, because I always need to get acquainted well with the issue at hand". In line, sample quotes "Boring" and "Foolish", illustrate unpleasant experiences.

\section{Social aspects of collective ideation: interaction and collaboration}

We found that collective ideation fosters interaction and collaboration in multiple ways. It fostered communication and led to good conversations, broke barriers between persons, and stimulated interaction. Sample quotes, "It led us to good conversation", "Communicative and egalitarian" It was even easier to start working with an unknown person than it sometimes tend to be with known person", and "It's a great way to broke barriers between persons and inside group", illustrate how the collective ideation was experienced by the respondents. In addition, collective ideation fostered people's mutuality and engagement in collective ideation, as the following samples show: "It forced me to throw into ideation and innovation with a positive way", "We encouraged each other", "We were very good team and inspired each other. It seemed as if we have been working together for years", and "It showed how easy it can be to find a shared practice and language". The findings show that the dyads developed collective practices to encourage each other and build on each other's contributions in a very short interaction through collective ideation. It also stimulated socialization and connectivity as people got to know each other: "This is a fun way to get to know new people and generate new ideas". The expression "It kept well the attention" indicates the group members were engaged in collective ideation. 


\section{Cognitive aspects of collective ideation}

In addition, we found that collective ideation fostered creative thinking among the respondents: "triggers thinking", "brainstorming" "out of the box", and "This really get your creativity going". It also stimulated collective creativity among people who considered themselves less creative, as the following samples show: "I thought I wasn't creative, but in collaboration with another you may be" and "Ideation together flows better than ideation alone". This experience was also expressed in reflective discussions conducted after each co-creation event.

Finally, we found that collective ideation made people's knowledge and skills accessible to others, of which the following quotes are examples: "This co-creation event demonstrated well mine and my team member's ability to start working quickly and exchange ideas boldly without knowing her personality", "You can learn about other person quite a lot in short time", "Counterpart can be surprisingly innovative", and "You learn to know other persons' logic of thinking, which helps communication". In addition to others' knowledge becoming accessible, the participants became aware of their own hidden abilities through collective ideation: "I learned to make a decision within a short time of period."

\section{Collective processes}

Our findings also show, that collective ideation and its organization yielded collective processes among the dyads. Participants worked in mutual relationships, supported each other, build on each others' contributions. Collective ideation helped to throw and engage into collective ideation. It helped in building shared understanding, shared practices and language, and directed attention to shared solution. (Appendix V)

\section{DISCUSSION}

The present study understood ideation as a collective phenomenon and introduced a novel method for stimulating collective ideation. Thus, the study highlights the importance of the social and affective aspects of collective ideation and creativity, aspects that have received less attention in cognition-focused ideation and facilitation of ideation specifically. As collective ideation occurs in interactions between people, in which novel ideas emerge, the social and affective aspects of creativity deserve more attention. To our knowledge, this view is novel and among the first aiming to foster ideation as a collective phenomenon through improvisation. We next discuss the theoretical and managerial contributions of the study and suggest avenues for future studies. 


\section{Theoretical contribution}

The present study contributes to the research on creativity and ideation by addressing the research gap in the current understanding of collective ideation and if fostering ideation as a collective phenomenon.

The study contributes to the knowledge creation theory (Nonaka and Takeuchi, 1995; Nonaka and Toyama, 2003) by presenting collective ideation as knowledge creation, which simultaneously is an unfolding social setting and an enacted collective practice. The interaction between people is vital for collective knowledge creation and ideation specifically, because it is the primary source of creativity and new knowledge (Sawyer and deZutter, 2009). Consequently, similar to knowledge creation, collective ideation is better understood as a process occurring as an evolving social setting (Nonaka and Toyama, 2003; Nonaka and von Krogh, 2009) and a collective practice (Orlikowski, 2009), which enables a new organization (Hjort, 2005) and space (Nonaka and Toyama, 2003) for new knowledge to emerge. Thus, the present study acknowledges the view that each creative process is unique (Elsbach and Kramer, 2003; Hargadon and Bechky, 2006; Hjort, 2004; Nemeth, 1997; Nonaka and Toyama, 2003; Nonaka and von Krogh, 2009), which results from a collectively enacted interaction among group members.

By viewing collective ideation as grounded by play through collective improvisation, the present study highlights the affective and social aspects of collective ideation and knowledge creation, aspects that have received less attention in facilitation of ideation. More specifically, as play is essentially about creativity (Csikszentmihalyi, 1988, 1999), and becoming as a part (engaging) of experience (Huizinga, 1949) the role of play in collective ideation is vital. Play reflects collectively enacted practices, processes, and atmosphere, which together create unique spaces for creativity (Elsbach and Kramer, 2003; Nonaka and Toyama, 2003; Nonaka and von Krogh, 2009). The empirical findings show that collective ideation stimulates affective (emotional experiences) and social (interaction, communication) aspects of collective ideation. Thus, collective ideation as an interpersonal and playful activity, rather than as a sequential idea treatment process, enables situational collective processes, which may raise unconventional connections and new knowledge from the interaction between people.

While presenting ideation as a collective endeavor, the study adds to the research on collective creativity (Hargadon and Bechky, 2006; Harvey, 2014; Harvey and Kou, 2013; Sawyer and deZutter, 2009). More specifically, this study contributes to research on creative synthesis (Harvey, 2014) by presenting that creative synthesis and integration of group members' knowledge, creativity, and perspectives can occur fast through playful interaction and collective improvisation. While doing so, 
it stimulates groups' creative potential and generation of new knowledge, and builds moments of collective creativity (Hargadon and Bechky, 2006) and serves well the generation of novel and outstanding insights specifically. Collective ideation shares similarities with synergistic creativity (Harvey, 2013; 2014; Harvey and Kou, 2013) by acknowledging the view that group members target their attention to build a single shared outcome by integrating the knowledge, creativity, and perspectives of group members (Harvey, 2014). Collective ideation is differentiated from synergistic creativity, by being fast and spontaneous ideation, rather than a process of thorough synthesis in which group members seek similarities to build on for a shared outcome (Harvey, 2014). Thus, collective ideation is a novel and different process with specific goals compared to creative synthesis (Harvey, 2014) and convergent creativity (Harvey, 2013). In this sense, collective ideation can be presented as collective brainstorming, as well.

According to Harvey (2014), the challenge of collective creativity is that group members do not necessarily recognize and engage in others' ideas. This kind of pro-social behavior is the cornerstone of any collective, like collective improvisation (Sawyer and deZutter, 2009; Spolin, 1979), and this study suggests that with conscious organization and facilitation collective ideation can be directed to support people's mutuality and interaction. When people are assigned to generate a shared single outcome within limited time, it is likely that they pay attention to and recognize others' ideas and to build on them. In other words, in collective ideation, no one owns ideas; instead, ideas are single contributions to build a shared creative outcome (idea concept). This kind of ideation is different from most ideation approaches (Diehl and Stroebe, 1987, 1991; Osborn, 1953; Paulus and Yang, 2000).

Further, the present study contributes to the research on convergent creativity (Harvey, 2013) by suggesting that collective ideation as an interdependent, social, and affective process is one kind of convergent creative process. In collective ideation, participants make decisions collectively in situ about the direction and actualization of the ideas (Choi et al., 2014; Harvey, 2014; Harvey and Kou, 2013; John-Steiner, 2000; Woodman et al., 1993), while striving toward a shared outcome. In such a process, idea generation, building on others' contributions, and evaluation of ideas occur in interactions between people in action, which refers to a convergent creative process.

Finally, the study extends our understanding of collective ideation and importantly contributes to research on group idea generation (Diehl and Stroebe, 1987; Nijstad et al., 2002; Osborn, 1953) by presenting ideation as a collective process, which is different from group processes focused on divergent and convergent thinking and sequential idea treatment activities. Thus, viewing ideation as a collective process contributes to the challenges of group ideation, because it is likely that until now identified challenges in group idea generation (Diehl and Stroebe, 1987, 1991; Nijstad and Stroebe, 
2006; Oldman and Baer, 2012) may reflect specific kinds of groups, idea generation processes, and desired outcomes (quantity of ideas). Thus, understanding ideation as a collective process transcends our understanding of group ideation in terms of the processes, goals, and outcomes.

\section{Practical contribution}

The practical contribution of the present study relies on the introduction of a novel method for fostering collective ideation as not only a cognitive but also a social and affective phenomenon.

The collective ideation assignment and organization embed several aspects that previous researchers have found foster idea generation, group creativity, and collective creativity specifically: the openness of the problem (Csikszentmihalyi, 1988; James, Clarks and Cropanzano, 1999; Sawyer and deZutter, 2009; Unsworth, 2002), a challenging goal (Litchfield, Fan and Brown, 2011; Locke and Latham, 1990), time limits (Osborn, 1953; Sawyer and deZutter, 2009), diversity of the group composition (Cohen and Levinthal, 1994; Harrison and Klein, 2007; Paulus and Yang, 2000), and playfulness (Dodgson, Salter and Gann, 2005; Huizinga, 1949; Mainemelis and Ronson, 2006). As the facilitation presented in this study is mainly embed in the assignment, it refers to a process-based approach (Harvey, 2014) for fostering collective ideation. In other words, it aims to build circumstances of collective improvisation and suggests that this type of circumstances with a sufficient assignment help the emergence of collective group processes and new knowledge from the interaction between people in situ. For example, the collective ideation assignment directs people's attention to a shared single idea (outcome), which fosters collective processes of interaction, such as collective attention, building on others' contributions, and enacting ideas.

With conscious organization of the collective idea generation (content, assignment, time, and goal setting), the cognitive, social, and emotional (affective) aspects of collective ideation can be stimulated. As it is likely that the groups do not naturally work collectively, and they often face many challenges (Diehl and Stroebe, 1987, 1991; Nijstad and Stroebe, 2006; Oldman and Baer, 2012), this novel collective ideation method can serve groups that aim to achieve novel ideas by integrating knowledge of diverse participants in a novel manner. In other words, collective ideation fosters group members to put their knowledge and creativity to use for a shared and collective outcome. Likewise, collective ideation provides an effective way for organizations to foster integration of the knowledge and creativity of diverse members to create new knowledge. Collective ideation as presented in this study is a potential and novel way to foster collective knowledge creation and generation of novel ideas. 
Further, managers and facilitators can use collective ideation in varied ways to boost generation of novel and outstanding ideas or solutions for various problems, such as product development. For example, when there is a need to solve problems of a particular target group (such as elderly people), collective ideation can be organized so that the all groups have the same target group (elderly people) and different other words (artefact and function). Thus, one collective ideation session can produce a large number of ideas for a specific group (elderly people). Another option is to use the same artefact for all groups and vary the other words, correspondingly. Then collective ideation produces a large number of ideas for a particular artefact within a short time.

Overall, the present collective ideation could serve managers and facilitators throughout complex and emergent innovation or knowledge creation process. Specifically, the collective ideation is a flexible and fast way to shift perspective, orchestrate knowledge and human creativity in a situational and contextual manner, which is important in collaborative multi-partner innovations.

In addition, as in collective ideation the emphasis is on stimulating social and affective aspects of human interaction, managers and facilitators can use this approach for various purposes and in many different situations. For example, it can be used to foster creativity and innovation, to integrate teams or units, HR development, team building, in daily work, and even to recruit new people, as our respondents suggested. As collective ideation highlights the social and affective aspects of interaction, it can be used as an ice-breaker and to transcend conventional and stable social practices and thus, in building space for creativity and novel solutions.

\section{CONCLUSIONS AND LIMITATIONS}

As creative outcomes are increasingly joint creations (Björk, 2012; Harvey, 2014; Sawyer and deZutter, 2009), the types of collaborations are increasingly varied in contemporary work life (Wagemen, Gardner and Mortenson, 2012). In addition, as each creative process is different (Elsbach and Kramer, 2003; Unsworth, 2001), there is a need for many approaches to support knowledge creation.

To conclude, the present study suggests that by paying attention to the social and emotional aspects of collective ideation in situ and with the conscious organization of the collective idea generation (content, assignment, time, and goal setting), the likelihood that the group uses its creative potential fully and produces novel and outstanding ideas will increase. Thus, any creative situation can benefit from temporary transcendence of the social space and boundaries of knowledge or a shift to a creative zone. The major contribution of the study lies in the introduction of the collective ideation method and bases for it, and thereby this study adds to the literature on knowledge creation and collective creativity. In addition, the empirical findings based on implementation of the collective 
ideation in several cases support our collective ideation design and show that it really stimulates interaction, emotional aspects state in a group, and idea generation, that is social, affective, and cognitive aspects of collective ideation. Thus, it can be useful for many types of knowledge creation.

The present study has several limitations. First, the facilitation method is an important initiative for fostering collective ideation, which requires further development to face the real collective creative challenges and creative outcomes. In other words, the impact of the facilitation method for producing useful and implemented ideas has not yet been measured and studied. Thus, future studies could develop the method further and measure its impact in real knowledge creation and innovation cases. Currently, facilitation as a highly imaginative and playful assignment better serves as an ice-breaker, stimulating interaction and interpersonal dynamics and creating space for collective ideation. However, we consider this method a fruitful tool for producing outstanding ideas collectively, and therefore, valuable for particular knowledge creation situations. For example, this method could resemble circumstances of innovation camps or other ideation activities that aim to integrated diverse stakeholders (customers, external partners, etc.) in organizations' innovation activities. Further, through the collective ideation, participant can learn about highly interdependent and collective creation, which is a less exercised and practiced form of creativity.

Second, while presenting the implementation of collective ideation, we present results of dyadic ideation, which may differentiate from groups' collective ideation. However, we first collected data from dyadic ideation, because it is the simplest group and enables study of interpersonal dynamics, that is, individual, interpersonal, and dyadic aspects of collective ideation. Then, we collected data from collective ideation within groups of three to five people, and the tentative findings regarding the participants' experiences are similar to the findings from the dyadic ideation. Thus, future studies should focus on fostering collective ideation in different sizes and different kinds of groups.

A third limitation could be the data collection, which mainly relied on open questions on a survey data. In future studies, dyadic or group collective ideation should be investigated by video or voice recording each dyad's or group's creative process, which enables study of the emergence of groups' collective creative processes.

\section{References}

Amin, A. and Roberts, J. (2008). Knowing in action: Beyond communities of practice. Research Policy, 37(2), pp. 353-369.

Bakeman, R., \& Beck, S. (1974). The size of informal groups in public. Environment and Behavior, 6(3), 378. 
Bantel, K. and Jackson, S. (1989). Top management and innovations in banking: Does the composition of the top team make a difference? Strategic Management Journal, 10(S1), pp. 107-124.

Barry, D. and Meisiek, S. (2010). Seeing more and seeing differently: Sensemaking, mindfulness, and the workarts. Organization Studies, 31(11), pp. 1505-1530.

Bartunek, J., Gordon, J. and Weathersby, R. (1983). Developing "complicated" understanding in administrators. Academy of Management Review, 8(2), pp. 273-284.

Björk, J. (2012). Knowledge domain spanners in ideation. Creativity and Innovation Management, 21(1), pp. 17-27.

Baruah, J. and Paulus, P. (2011). Category assignment and relatedness in the group ideation process. Journal of Experimental Social Psychology, 47(6), pp. 1070-1077.

Björk, J., Di Vincenzo, F., Magnusson, M. and Mascia, D. (2011). The impact of social capital on ideation. Industry and Innovation, 18(6), pp. 631-647.

Björk and Magnusson, (2016). The What, Who, When, Where, and How of idea assessment. Paper presented at the ISPIM Innovation Forum, Boston, MA, USA on 13-16 March, 2016.

Brown, V., Tumeo, M., Larey, T. and Paulus, P. (1998). Modeling cognitive interactions during group brainstorming. Small Group Research, 29(4), pp. 495-526.

Catmull, E. (2008). How Pixar fosters collective creativity. Boston: Harvard Business School Publishing. Choi, J., Sung, S. and Cho, T. (2014). Creative contribution of individuals in groups: Effects of goal orientation and participative safety. Social Behavior and Personality: An International Journal, 42(3), pp. 407-422.

Cohen, W. M., \& Levinthal, D. A. (1994). Fortune favors the prepared firm. Management science, 40(2), 227-251.

Cook, S. and Brown, J. (1999). Bridging epistemologies: The generative dance between organizational knowledge and organizational knowing. Organization Science, 10(4), pp. 381-400.

Csikszentmihalyi, M. (1988). Motivation and creativity: Toward a synthesis of structural and energistic approaches to cognition. New Ideas in Psychology, 6(2), pp. 159-176.

Csikszentmihalyi, M. (1999). Implications of a systems perspective for the study of creativity. In: R. Sternberg (ed.), Handbook of creativity. City: Cambridge University Press, p. 313.

Diehl, M. and Stroebe, W. (1987). Productivity loss in brainstorming groups: Toward the solution of a riddle. Journal of Personality and Social Psychology, 53(3), p. 497.

Diehl, M. and Stroebe, W. (1991). Productivity loss in idea-generating groups: Tracking down the blocking effect. Journal of Personality and Social Psychology, 61(3), p. 392.

Denzin, N. L., \& Lincoln, Y. Y. (1994). Handbook of Qualitative Research, Sage Publications, Inc., USA Dodgson, M., Salter, A. and Gann, D. (2005). Think, play, do. Oxford University Press.

Drazin, R., Glynn, M. and Kazanjian, R. (1999). Multilevel theorizing about creativity in organizations: A sensemaking perspective. Academy of Management Review, 24(2), pp. 286-307.

Ekvall, G. (1996). Organizational climate for creativity and innovation. European journal of work and organizational Psychology, 5(1), pp. 105-123.

Elsbach, K. D., \& Kramer, R. M. (2003). Assessing creativity in Hollywood pitch meetings: Evidence for a dual-process model of creativity judgments. Academy of Management journal, 46(3), 283-301.

Erden, Z., Von Krogh, G. and Nonaka, I. (2008). The quality of group tacit knowledge. The Journal of Strategic Information Systems, 17(1), pp. 4-18.

Eriksson, P., \& Kovalainen, A. (2015). Qualitative methods in business research: A practical guide to social research. $2^{\text {nd }}$ Edition, London, Sage.

Gadamer, H. (1989). Play as the clue to ontological explanation. Truth and method, Crossroad. New York, NY.

Grant, A. M., \& Berry, J. W. (2011). The necessity of others is the mother of invention: Intrinsic and prosocial motivations, perspective taking, and creativity. Academy of management journal, 54(1), 73-96. 
Grawitch, M., Munz, D. and Kramer, T. (2003). Effects of member mood states on creative performance in temporary workgroups. Group Dynamics: Theory, Research, and Practice, 7(1), p. 41.

Gray, B. (1989). Collaborating: Finding common ground for multiparty problems. Jossy-Bass, San Francisco.

Guzzo, R. and Dickson, M. (1996). Teams in organizations: Recent research on performance and effectiveness. Annual Review of Psychology, 47(1), pp. 307-338.

Hammond, M., Neff, N., Farr, J., Schwall, A. and Zhao, X. (2011). Predictors of individual-level innovation at work: A meta-analysis. Psychology of Aesthetics, Creativity, and the Arts, 5(1), p. 90.

Handzic, M. and Chaimungkalanont, M. (2004), "Enhancing Organisational Creativity through Socialisation", Electronic Journal of Knowledge Management, Vol 2., Issue 1, December, pp. 57-64.

Hargadon, A. B. (2002). Brokering knowledge: Linking learning and innovation. Research in Organizational behavior, 24, 41-85.

Hargadon, A. and Bechky, B. (2006). When collections of creatives become creative collectives: A field study of problem solving at work. Organization Science, 17(4), pp. 484-500.

Harrington, D. M. (1975). Effects of explicit instructions to "be creative" on the psychological meaning of divergent thinking test scores 1. Journal of personality, 43(3), 434-454.

Harrison, D. and Klein, K. (2007). What's the difference? Diversity constructs as separation, variety, or disparity in organizations. Academy of Management Review, 32(4), pp. 1199-1228.

Harvey, S. (2013). A different perspective: The multiple effects of deep level diversity on group creativity. Journal of Experimental Social Psychology, 49(5), pp. 822-832.

Harvey, S. (2014). Creative synthesis: Exploring the process of extraordinary group creativity. Academy of Management Review, 39(3), pp. 324-343.

Harvey, S. and Kou, C. (2013). Collective engagement in creative tasks: The role of evaluation in the creative process in groups. Administrative Science Quarterly, 58(3), pp. 346-386.

Hatchuel, A., \& Weil, B. (2009). CK design theory: an advanced formulation. Research in engineering design, 19(4), 181.

Hjorth, D. (2004). Creating space for play/invention-concepts of space and organizational entrepreneurship. Entrepreneurship \& Regional Development, 16(5), 413-432.

Hjort, D. (2005). Organizational entrepreneurship: with De Certeau on creating heterotopias (or spaces for play). Journal of Management Inquiry, 14(4), pp. 386-398.

Heslin, P. (2009). Better than brainstorming? Potential contextual boundary conditions to brainwriting for idea generation in organizations. Journal of Occupational and Organizational Psychology, 82(1), pp. 129145.

Huizinga, J. (1949). Homo Ludens. A study of the play-element in culture. London, Routledge \& Kegan Paul.

James, K., Clark, K. and Cropanzano, R. (1999). Positive and negative creativity in groups, institutions, and organizations: A model and theoretical extension. Creativity Research Journal, 12(3), pp. 211-226.

John-Steiner, V. (2000). Creative collaboration. Oxford: Oxford University Press.

Johnstone, K. (1979/2015). IMPRO. Improvisation and the theatre. New York: Routledge/Theatre Arts Books.

Kohn, N., Paulus, P. and Choi, Y. (2011). Building on the ideas of others: An examination of the idea combination process. Journal of Experimental Social Psychology, 47(3), pp. 554-561.

Koppett, K. (2001). Training to imagine: Practical, improvisational techniques to inspire creativity, enhance communication and develop leadership. Google Scholar.

Kurtzberg, T. and Amabile, T. (2001). From Guilford to creative synergy: Opening the black box of teamlevel creativity. Creativity Research Journal, 13(3-4), pp. 285-294.

Litchfield, R., Fan, J. and Brown, V. (2011). Directing idea generation using brainstorming with specific novelty goals. Motivation and Emotion, 35(2), pp. 135-143.

Locke, E. and Latham, G. (1990). A theory of goal setting \& task performance. City: Prentice-Hall, Inc. 
MacKinnon, D. W. (1962). The nature and nurture of creative talent. American psychologist, 17(7), 484. Mainemelis, C., and Ronson, S. (2006). Ideas are born in fields of play: Towards a theory of play and creativity in organizational settings. Research in Organizational Behavior, 27, pp. 81-131.

Montuori, A. (2003). The complexity of improvisation and the improvisation of complexity: Social science, art and creativity. Human Relations, 56(2), pp. 237-255.

Moorman, C. and Miner, A. (1998). The convergence of planning and execution: Improvisation in new product development. The Journal of Marketing, pp. 1-20.

Nemeth, C. (1986). Differential contributions of majority and minority influence. Psychological Review, 93(1), p. 23.

Nijstad, B. and Stroebe, W. (2006). How the group affects the mind: A cognitive model of idea generation in groups. Personality and Social Psychology Review, 10(3), pp. 186-213.

Nijstad, B., Stroebe, W. and Lodewijkx, H. (2002). Cognitive stimulation and interference in groups: Exposure effects in an idea generation task. Journal of Experimental Social Psychology, 38(6), pp. 535544.

Nisula, A. M., \& Kianto, A. (2018). Stimulating organisational creativity with theatrical improvisation. Journal of Business Research, 85, 484-493.

Nonaka, I., and Takeuchi, H. (1995). The knowledge-creating company: How Japanese companies create the dynamics of innovation. Oxford University Press.

Nonaka, I., and Toyama, R. (2003). The knowledge-creating theory revisited: knowledge creation as a synthesizing process. Knowledge Management Research \& Practice, 1(1), pp. 2-10.

Nonaka, I., and Von Krogh, G. (2009). Perspective-Tacit knowledge and knowledge conversion: Controversy and advancement in organizational knowledge creation theory. Organization Science, 20(3), pp. 635-652.

Oikarinen, T. and Kallio, A. (2012) 'Absorption and creation of new knowledge: a multi-case study of different forms of knowledge impacting on absorptive capacity', Presented at $O L K C$, Valencia, 25-27 April 2012

Oldham, G. and Baer, M. (2012). Creativity and the work context. In: M. Mumford (ed.), Handbook of organizational creativity. London: Elsevier Academic Press, pp. 387-413.

Osborn, A. (1953). Applied imagination. Oxford: Scribner's.

Paulus, P. and Yang, H. (2000). Idea generation in groups: A basis for creativity in organizations. Organizational Behavior and Human Decision Processes, 82(1), pp. 76-87.

Phillips, N. (1995) 'Telling organizational tales: on the role of narrative fiction in the study of organizations', Organization Studies, Vol. 16, No. 4, pp.625-649.

Roos, J. and Roos, M. (2006) 'Play is the key', in Roos, J. (Ed.): Thinking from Within. A Hands-on Strategy Practice, Palgrave Macmillan, USA.

Runco, M. (2010). Divergent thinking, creativity, and ideation. In: J. Kaufman and R. Steinberg (eds.), The Cambridge handbook of creativity. Cambridge: Cambridge University Press, pp. 413-446.

Sawyer, R., Csikszentmihalyi, M., John-Steiner, V., Moran, S., Feldman, D., Gardner, H., Sternberg, R. and Nakamura, J. (Series eds.). (2003). Creativity and development. Counterpoints: Cognition, memo. New York: Oxford University Press.

Sawyer, R. and DeZutter, S. (2009). Distributed creativity: How collective creations emerge from collaboration. Psychology of Aesthetics, Creativity, and the Arts, 3(2), p. 81.

Shalley, C. (1991). Effects of productivity goals, creativity goals, and personal discretion on individual creativity. Journal of Applied Psychology, 76(2), pp. 179.

Simonton, D. K. (1999). Creativity as blind variation and selective retention: Is the creative process Darwinian?. Psychological Inquiry, 309-328.

Spolin, V. (1977). Improvisation for the theater. A Handbook of Teaching and Directing Techniques, Pitman Publishing Limited, UK. City: Publisher. 
Unsworth, K. (2001). Unpacking creativity. Academy of Management Review, 26(2), pp. 289-297.

Van Dyck, C., Frese, M., Baer, M., \& Sonnentag, S. (2005). Organizational error management culture and its impact on performance: A two-study replication. Journal of applied psychology, 90(6), 1228.

Van Knippenberg, D. and Schippers, M. (2007). Work group diversity. Annual Review of Psychology, 58, pp. 515-541.

Wageman, R., Gardner, H. and Mortensen, M. (2012). The changing ecology of teams: New directions for teams research. Journal of Organizational Behavior, 33(3), pp. 301-315. 
ASSIGNMENT FOR COLLECTIVE IDEATION

The task of your group is to create a business idea concept from incidental ingredients as described below.

\section{TASK}

PART I: IDEATION

Duration 25-30 min

You will get three random elements/words:

1. Object/artefact

2. Function

3. Target group (users for whom you create the solution)

These three words (elements) are ingredients for your ideation work, and all these elements need to be involved in your final solution in one way or another.

IA: IDEATE AND CO-CREATE a product, process or service concept by using the object/artefact and function elements (words 1 and 2) for your target group or users (word 3). Be imaginative!

IB: ILLUSTRATE AND PRESENT your idea on paper (pictures, sketch, text, etc.) and be prepared to pitch (explain and sell) it to the audience (class) - e.g., what the product or solution is, how it serves the target group, and what the business model is for commercializing it. Imagine, that you are seeking funding for your product/solution ( $€ 50000)$ for further development and testing of your product and the related business model.

\section{PART II: PITCH}

In the pitch, describe and sell your solution to the audience (investors). Prepare a short presentation ( 2 min max) about your solution (by using sketches or other illustrations).

\section{Part III: CROWD EVALUATION}

Peer-to-peer (or crowd) evaluation according to instruction 
APPENDIX II

Table: Implemented collective ideation cases (2013-2017)

\begin{tabular}{|c|c|c|c|c|c|}
\hline & Case & Year & Partici & Respond & Type* \\
\hline 1 & Working Adult University Students/M.Sc. (Economics \& Engineering) & 2013 & 44 & 14 & S \\
\hline 2 & Adult Working University Students/MBA & 2013 & 15 & 9 & S \\
\hline 3 & Working Adult University Students/M.Sc. (Economics \& Engineering) & 2013 & 28 & 27 & S \\
\hline 4 & Working Adult University Students/Applied social sciences & 2014 & 22 & 20 & S \\
\hline 5 & Working Adult University Students/M.Sc. (Economics \& Engineering) & 2014 & 25 & 24 & S \\
\hline 6 & City I/Large & 2015 & 75 & 65 & $\mathrm{O}$ \\
\hline 7 & City II/Large & 2015 & 28 & 25 & $\mathrm{O}$ \\
\hline 8 & University Students/M.Sc. (Economics \& Engineering), International & 2015 & 27 & 27 & S \\
\hline 9 & Working Adult University Students/M.Sc. (Economics \& Engineering) & 2016 & 34 & 29 & S \\
\hline 10 & Large Technology Company & 2016 & 48 & 44 & $\mathrm{O}$ \\
\hline 11 & Working Adult University Students/M.Sc. & 2017 & 35 & 29 & S \\
\hline 12 & Adult Working University Students/MBA & 2017 & 10 & 8 & S \\
\hline 13 & Working Adult University Students/M.Sc. (Economics \& Engineering) & 2017 & 50 & 48 & S \\
\hline & Total & & 441 & 369 & \\
\hline
\end{tabular}

$* \mathrm{~S}=$ Student case; $\mathrm{O}=$ Organization case 
Table: Positive experiences

APPENDIX

III

\begin{tabular}{|c|c|c|c|}
\hline & $2^{\text {nd }}$ round concept & $1^{\text {st }}$ round concept & Sample expressions \\
\hline \multirow[t]{8}{*}{$\begin{array}{l}\text { POSITIVE } \\
\text { EXPERIENCES }\end{array}$} & \multirow[t]{6}{*}{$\begin{array}{l}\text { Emotionally positive experience, playful, } \\
\text { joy, fun, inspiring, pleasure }\end{array}$} & Fun & $\begin{array}{l}\text { "Fun", "lot of fun", "great fun", } \\
\text { "Nice and fun co-creation event, } \\
\text { usually people utilize humor to } \\
\text { manage this kind of co-creation } \\
\text { events". }\end{array}$ \\
\hline & & Nice & $\begin{array}{l}\text { "Nice", "nice co-creation event", } \\
\text { "it was nice", "nice experience" }\end{array}$ \\
\hline & & Interesting & $\begin{array}{l}\text { "Interesting"; "Interesting and } \\
\text { creative! Some brilliant ideas can } \\
\text { be triggered here!" }\end{array}$ \\
\hline & & Inspiring & Inspiring \\
\hline & & Good/great & $\begin{array}{l}\text { "Good," "good co-creation } \\
\text { event", "great"; } \\
\text { "The pitches part is really good. } \\
\text { Really timely and helps to test } \\
\text { and stimulate one's potential" } \\
\text { "Well organized, it kept the } \\
\text { attention well". }\end{array}$ \\
\hline & & Pleasurable & $\begin{array}{l}\text { "pleasurable experience", } \\
\text { "enjoyable", "I like", "I liked", "I } \\
\text { love this experience" }\end{array}$ \\
\hline & New and fresh experience & $\begin{array}{l}\text { Refreshing } \\
\text { Different } \\
\text { Variation } \\
\text { New } \\
\text { Surprising }\end{array}$ & $\begin{array}{l}\text { "Variation from familiar work", } \\
\text { "Nice variation", "I experienced } \\
\text { this as new compared to on what } \\
\text { I am familiar with"; "Awesome"; } \\
\text { "Different way to ideate and } \\
\text { make impossible possible" } \\
\text { "Different exercise is good for } \\
\text { you" } \\
\text { "New co-creation event, new } \\
\text { wonderful companionship" } \\
\text { "Energizing" }\end{array}$ \\
\hline & Expanding experiences & $\begin{array}{l}\text { Breaking boundaries } \\
\text { Creative thinking } \\
\text { Liberating } \\
\text { First difficult - then inspiring }\end{array}$ & $\begin{array}{l}\text { "triggers thinking"; "eye- } \\
\text { opening"; "out of the box"; } \\
\text { "open-minded"; "Breaking one's } \\
\text { boundaries"; "Stimulates } \\
\text { thinking" "Creates thinking and } \\
\text { how to sell quickly your items"; } \\
\text { "Creative - let it go, fly!"; "First } \\
\text { difficult - then I got inspired" }\end{array}$ \\
\hline \multirow[t]{2}{*}{$\begin{array}{l}\text { CONTRADICTORY } \\
\text { EXPERIENCES }\end{array}$} & \multirow[t]{2}{*}{ Unpleasant experiences } & Difficult & $\begin{array}{l}\text { "Difficult", "Difficult (I am not } \\
\text { familiar with this)" }\end{array}$ \\
\hline & & $\begin{array}{l}\text { Not for me } \\
\text { Too fast } \\
\text { Didn't like }\end{array}$ & $\begin{array}{l}\text { "I like larger groups"; } \\
\text { "We must have been on different } \\
\text { wavelength, or at least we could } \\
\text { not connect [at the cognitive } \\
\text { level]. As a human she is } \\
\text { certainly ok". } \\
\text { "We had too little time" } \\
\text { "Boring - took too much time", } \\
\text { "a little bit foolish", } \\
\text { "Business oriented, not used in } \\
\text { social and health care sector". }\end{array}$ \\
\hline
\end{tabular}




\begin{tabular}{|c|c|c|c|}
\hline & $2^{\text {nd }}$ round concept & $1^{\text {st }}$ round (concept) & Examples of expressions \\
\hline \multirow[t]{6}{*}{$\begin{array}{l}\text { SOCIAL } \\
\text { INTERACTION }\end{array}$} & COMMUNICATION & Communicative & $\begin{array}{l}\text { "Communicative", "it lead us to } \\
\text { a good conversation" "Supports } \\
\text { familiarization", } \\
\text { "Communicative } \\
\text { egalitarian" } \\
\text { "Led to good conversation", }\end{array}$ \\
\hline & SOCIALIZATION & Get to know each other & $\begin{array}{l}\text { "Interactive - I got to know a } \\
\text { new person" } \\
\text { "This is fun way to get to know } \\
\text { new people and generate new } \\
\text { ideas" }\end{array}$ \\
\hline & \multirow[t]{2}{*}{ TRANSCENDES INTERACTION } & Break barriers between people & $\begin{array}{l}\text { "It's a great way to broke barriers } \\
\text { between persons and inside } \\
\text { group" }\end{array}$ \\
\hline & & Interactive & $\begin{array}{l}\text { "It was even easier to start } \\
\text { working with an unknown person } \\
\text { than it sometimes tend to be with } \\
\text { known person." } \\
\text { "Interactive...." }\end{array}$ \\
\hline & TRUST & Trust & $\begin{array}{l}\text { "You have to trust. You have to } \\
\text { trust your creativity and your } \\
\text { team members' creativity". }\end{array}$ \\
\hline & & & $\begin{array}{l}\text { "new way to facilitate creativity } \\
\text { and turn it into a product" }\end{array}$ \\
\hline \multirow[t]{4}{*}{ COGNITON } & \multirow[t]{3}{*}{ MAKES KNOWLEDE AND SKILLS VISIBLE } & Reveals skills & $\begin{array}{l}\text { "I learned to make decision in } \\
\text { short time of period" }\end{array}$ \\
\hline & & Reveals abilities & $\begin{array}{l}\text { "This co-creation event } \\
\text { demonstrated well mine and my } \\
\text { team member's ability to start } \\
\text { working quickly and exchange } \\
\text { ideas boldly without knowing her } \\
\text { personality." }\end{array}$ \\
\hline & & $\begin{array}{l}\text { Brings knowledge and skills } \\
\text { accessible }\end{array}$ & $\begin{array}{l}\text { "counterpart can be surprisingly } \\
\text { innovative", } \\
\text { "You can learn about other } \\
\text { person quite a lot in short time" } \\
\text { "facilitates knowledge sharing } \\
\text { and ideation. It gives a good } \\
\text { feeling when shared idea is } \\
\text { found" } \\
\text { "It was great to change ideas wit } \\
\text { someone unfamiliar to you" } \\
\text { "You learn to know other } \\
\text { persons' logic of thinking, which } \\
\text { makes communication easier" }\end{array}$ \\
\hline & COLLECTIVE CREATIVITY & Stimulates creativity & $\begin{array}{l}\text { "This can really get your } \\
\text { creativity going", I thought I } \\
\text { wasn't creative, but with } \\
\text { collaboration with another you } \\
\text { may be!", } \\
\text { "Thanks for remaining to be } \\
\text { innovative and open mind!" }\end{array}$ \\
\hline
\end{tabular}




\begin{tabular}{|c|c|c|c|}
\hline & $2^{\text {nd }}$ round concept & $1^{\text {st }}$ round (concept) & Examples of expressions \\
\hline \multirow{6}{*}{$\begin{array}{l}\text { COLLECTIVE } \\
\text { PROCESSES }\end{array}$} & ATTENTION & Attention & "It kept well attention" \\
\hline & $\begin{array}{lll}\text { ENGAGEMENT } & \text { INTO } & \text { COLLECTIVE } \\
\text { IDEATION } & & \end{array}$ & Forces to throw into ideation & $\begin{array}{l}\text { "A nice and positive way to force } \\
\text { one into ideation and innovation" } \\
\text { "It was nice to let ideas flow - we } \\
\text { had very appreciative and } \\
\text { humorous climate" } \\
\text { "Effective in throwing into } \\
\text { action and in opening group } \\
\text { work" }\end{array}$ \\
\hline & MUTUALITY & $\begin{array}{l}\text { Support each other } \\
\text { Building on others' contributions }\end{array}$ & $\begin{array}{l}\text { "We encouraged each other" } \\
\text { "point of view was broader and } \\
\text { other person one said something } \\
\text { other than what I had thought } \\
\text { about and the ideas was further } \\
\text { developed in my head" } \\
\text { "We were very good team and } \\
\text { inspired each other. It seemed as } \\
\text { if we have been working together } \\
\text { for years" }\end{array}$ \\
\hline & SHARED VIEW & Shared understanding & $\begin{array}{l}\text { "Showed, how easy it was to find } \\
\text { a shared understanding" } \\
\text { "Natural and fluent - it was easy } \\
\text { to find a shared practice and } \\
\text { language" }\end{array}$ \\
\hline & COMMITMENT SHARED IDEA & Shared outcome & $\begin{array}{l}\text { "it was good and creative } \\
\text { solutions here made in the class" } \\
\text { "given words were difficult, but } \\
\text { we succeeded to invent nice } \\
\text { solution" }\end{array}$ \\
\hline & & & $\begin{array}{l}\text { "new way to facilitate creativity } \\
\text { and turn it into a product" }\end{array}$ \\
\hline
\end{tabular}

